Check for updates

Cite this: RSC Adv., 2018, 8, 1753

Received 27th September 2017 Accepted 21st December 2017

DOI: $10.1039 / c 7 r a 10694 g$

rsc.li/rsc-advances

\section{Controlled synthesis of Cu nanoparticle arrays with surface enhanced Raman scattering effect performance $\uparrow$}

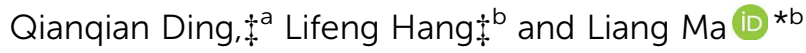

Herein, we report the synthesis of a $350 \mathrm{~nm}$ Cu nanoparticle array with different period combinations by a method based on a monolayer and have further investigated its surface-enhanced Raman scattering (SERS) properties experimentally. The SERS properties of the $350 \mathrm{~nm} \mathrm{Cu}$ nanoparticle array were investigated, and the influence of the thickness of the $\mathrm{Cu}$ nanoshell was studied. The results demonstrated that the $18 \mathrm{~min}$ ion-sputtering deposition can improve the SERS activity in addition to good stability. This study can provide an optimized method for some inexpensive nanomaterials as highly active SERS substrates and a good solution to the interference caused by substrate impurity.

\section{Introduction}

SERS has attracted significant attention as it is a highly sensitive analytical technique, and it has already been widely employed in a variety of fields including analytical chemistry, environmental monitoring, medical science, and explosives analysis. ${ }^{1-3}$ As is known, the SERS phenomenon is observed primarily from the surface of $\mathrm{Au}, \mathrm{Ag}, \mathrm{Cu}$, and other noble metals. ${ }^{\mathbf{4}, 5}$ It is generally believed that Ag-based substrates may provide highest electromagnetic enhancement leading to a large enhancement of Raman intensity, but they have intrinsically low chemical stability towards surface oxidation, which greatly hinders their application in various fields. ${ }^{6}$ In contrast, Au-based SERS substrates have long-term stability although they can provide moderate enhancement in SERS experiments. ${ }^{7}$ However, the $\mathrm{Au}$ and $\mathrm{Ag}$ materials are too expensive to come into practice. Therefore, development of new substrates with low price and better stability is of great significance. Among all the metals, Cu nanomaterials have the similar localized surface plasmon resonance (LSPR) effect as the $\mathrm{Au}$ and $\mathrm{Ag}$ nanomaterials. ${ }^{\mathbf{8 - 1 0}}$ Moreover, $\mathrm{Cu}$ nanomaterials are rich in the earth's crust and inexpensive. Therefore, $\mathrm{Cu}$ is expected to replace these noble metals in many different areas such as in catalysis, surface-enhanced Raman scattering, and so on. ${ }^{11-13}$

\footnotetext{
${ }^{a}$ Department of Precision Manufacturing Engineering, Suzhou Vocational Institute of Industrial Technology, Suzhou 215104, China

${ }^{b}$ Department of Polymer Science and Engineering, School of Chemistry and Materials Science, University of Science and Technology of China, Hefei 230026, P. R. China. E-mail: maliangs@mail.ustc.edu.cn

$\dagger$ Electronic supplementary information (ESI) available. See DOI: 10.1039/c7ra10694g

\$ These authors contributed equally to this work.
}

At present, $\mathrm{Cu}$ nanoparticles are normally prepared by the reduction of a $\mathrm{Cu}$ precursor and solution condition. $\mathrm{Cu}$ nanoparticles are normally prepared through $\mathrm{Cu}$ ion reduction. This method needs surfactants for stability. It is still difficult to achieve large area mono-dispersion when chemical reduction method is used to prepare $\mathrm{Cu}$ nanoparticles. ${ }^{\mathbf{1 4 , 1 5}}$ Other methods to prepare nanoparticles are grinding or thermally evaporating the solid $\mathrm{Cu}^{16}$ The disadvantage of this method is the difficulty to control the morphology of the nanoparticles. Therefore, the preparation method of a $\mathrm{Cu}$ array with an ordered structure is still very challenging.

In this research, polystyrene spheres (PS) were used as a template, and the outer shell of $\mathrm{Cu}$ was obtained based on the PS monolayer colloidal crystal template via the ion-sputtering deposition method (strategy shown in Fig. 1). The SERS activity of these $\mathrm{Cu}$ nanoparticles was evaluated using crystal violet (CV) and 4-aminothiophenol (4-ATP) as the probe molecules. The experimental result shown was that the 18 min ionsputtering deposition could improve the SERS activity in addition to good stability. This study provides an effective way to prepare an inexpensive $\mathrm{Cu}$ SERS substrate, which can provide an optimized method for using $\mathrm{Cu}$ as a highly active SERS substrate.

\section{Experimental}

\subsection{Preparation of the $\mathrm{Cu}$ nanosphere array}

The $\mathrm{Cu}$ nanosphere arrays were prepared through the ionsputtering method, and the synthetic process is shown in Fig. 1. At first, the $350 \mathrm{~nm}$ uniform monolayer colloidal PS crystal was synthesized on a piece of well cleaned glass slide by the gas-liquid-solid interface self-assembly method, as illustrated in previous research. ${ }^{\mathbf{1 7 , 1 8}}$ After drying at room temperature, a copper layer was successively deposited on it using the 


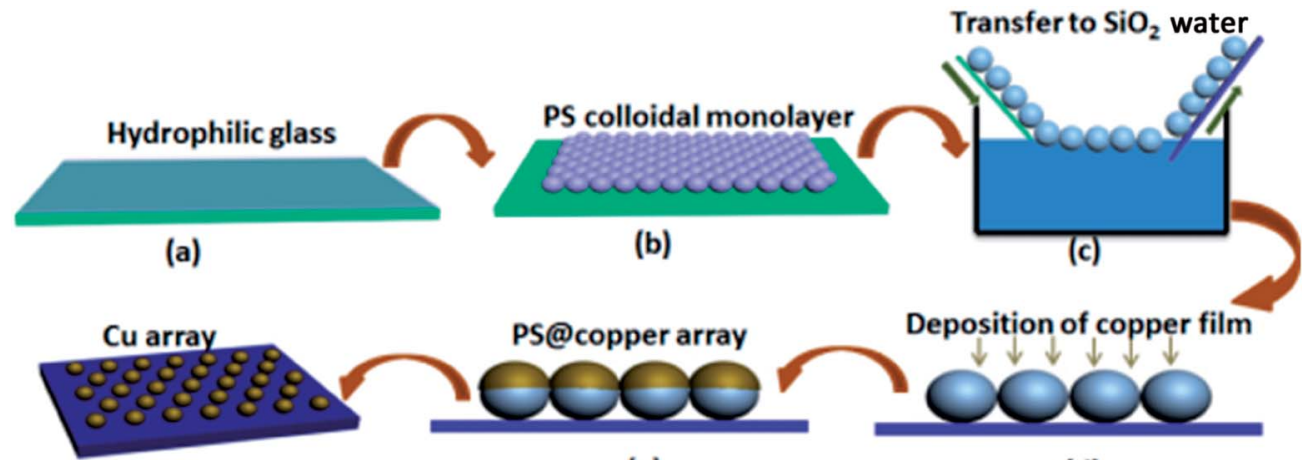

(f)

(e)

(d)

Fig. 1 Schematic of the preparation of the Cu nanosphere array. (a) The hydrophilic glass substrate with a layer of water; (b) a PS monolayer colloidal crystal was fabricated on a cleaned glass slide by an air/water interfacial self-assembly method; (c) PS microsphere array was transferred onto the $\mathrm{SiO}_{2}$ substrate through liquid surface transfer; $(\mathrm{d}-\mathrm{e})$ microsphere array after ion-sputtering deposition of the Cu film on the surface of the PS nanosphere array; (f) the PS colloidal array with Cu coating was annealed under a protective atmosphere, and the Cu nanosphere array was formed on the $\mathrm{SiO}_{2}$ substrate.

ion-sputtering deposition method. After this, we optimized the sputtering time, and a series of microsphere arrays with different particle sizes was obtained.

\subsection{Characterization}

The morphology of the Cu microsphere array was characterized by FE-SEM (S-4700, Hitachi, Japan) and X-ray energy dispersive spectroscopy (EDS) at an acceleration voltage of $200 \mathrm{kV}$. Transmission electron microscopy (TEM) images were obtained by the JEOL 2010 high resolution transmission electron microscope operating at an acceleration voltage of $200 \mathrm{kV}$. Raman spectra were obtained using a confocal microscope Raman system (LabRAM HR800, Horiba Jobin Yvon, Japan) at $532 \mathrm{~nm}$. The radiation generated by an air-argon ion laser (Spectra-Physics model 163-C4260) was the excitation source.

\section{Results and discussion}

\subsection{Cu microsphere array}

Fig. 1 shows the synthetic process of the $\mathrm{Cu}$ nanosphere array. The uniform $350 \mathrm{~nm}$ polystyrene sphere (PS) monolayer colloidal crystal was fabricated on a piece of well cleaned glass slide by the self-assembly method of air/water interface. Fig. $\mathrm{S} 1 \dagger$ displays the SEM images of the $350 \mathrm{~nm}$ PS colloidal monolayer on the glass slide, which shows the hexagonal close-packed alignment. The PS@Cu composite nanosphere array was thus obtained via successively ion-sputtering deposition of $\mathrm{Cu}$ on the PS colloidal monolayer with different thicknesses. Upon comparing the SEM images of the PS nanosphere and PS@Cu composite microsphere from the tilted view, we found that the PS nanosphere was smooth, and the surface of the PS@Cu microsphere was rough. The round nanosphere changed to elliptic morphology, as shown in Fig. 2b. The PS@Cu composite microsphere array was calcined under a protective atmosphere at $900{ }^{\circ} \mathrm{C}$ for $2 \mathrm{~h}$. During the annealing process, each PS sphere was removed from the array, and most of $\mathrm{Cu}$ coated on it when the surface of the sphere was melted and formed a spherical nanoparticle. This was driven by the in situ principle of surface free energy minimum. The different stages about the annealing processes of the copper nanospheres are shown in Fig. S2. $\dagger$ When the temperature was increased, the copper film shrank to form spherical Cu NPs in situ from a spherical shell to spherical nanoparticles. Hence, the $\mathrm{Cu}$ nanosphere array was developed on the $\mathrm{SiO}_{2}$ substrate. Fig. $2 \mathrm{c}$ and d show the SEM images of $\mathrm{Cu}$ nanoparticles with a periodic length of $350 \mathrm{~nm}$ observed from the top and tilted view, respectively. We observed the $\mathrm{Cu}$ nanoparticles with a size of $c a .110 \mathrm{~nm}$ with the hexagonal nonclosed-packed (hncp) arrangement. The whole $\mathrm{Cu}$ nanosphere array maintained a good order on the $\mathrm{SiO}_{2}$ substrate. Moreover, energy dispersive spectrometry (EDS) of the $\mathrm{Cu}$ nanoparticles indicates that the sample only contains two elements: $\mathrm{Cu}$ and $\mathrm{Si}$, as shown in the inset images of Fig. S3. $\dagger$

TEM images in Fig. 3 show a typical surface morphology of $\mathrm{Cu}$ nanoparticles. From the TEM image, we have found that the $\mathrm{Cu}$ nanoparticles have an obvious spherical shape and uniform
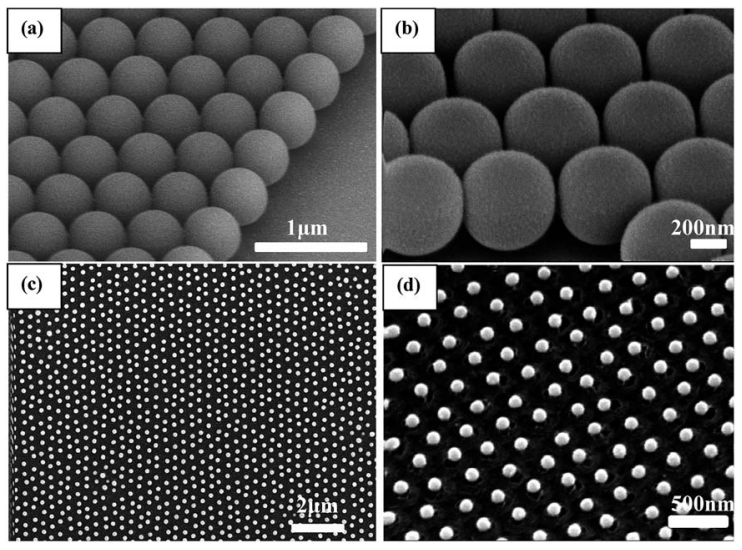

Fig. 2 (a) SEM images observed from the tilted view of the $350 \mathrm{~nm}$ PS monolayer colloidal crystal and PS aCu composite microsphere (b); (c) SEM images of $\mathrm{Cu}$ nanoparticles with a periodic length of $350 \mathrm{~nm}$ observed from the top view; and (d) SEM images of Cu nanoparticles with a periodic length of $350 \mathrm{~nm}$ observed from the tilted view. 

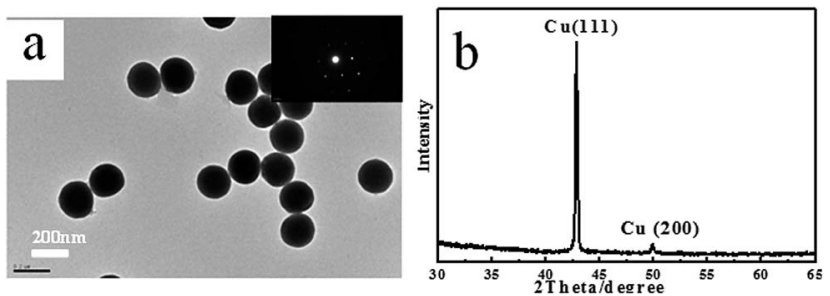

Fig. 3 (a) TEM images of Cu nanoparticles and (b) XRD patterns of the Cu nanoparticles.

size, and the surface is very smooth without any impurities. The selected area electronic diffraction (SAED) is used to accomplish the micro morphology observation and electron diffraction. The diffraction pattern shown in Fig. 3a has very symmetrical diffraction spots, which indicates that nanoparticles are single crystals. Further analysis of the particles shows that the single crystal has face-centred-cubic (FCC) structures. The samples were also characterized by X-ray diffraction (XRD). The identified $\mathrm{Cu}$ peaks were assigned to the face-centred cubic structures, and the peaks at $42.8^{\circ}$ and $49.9^{\circ}$ were attributed to (111) and (200), respectively.

We adjusted the deposition time to control the size of the $\mathrm{Cu}$ nanoparticles. Controlling the thickness of the deposition plays a key role in forming an orderly nanoparticles array. When the thickness of the deposited $\mathrm{Cu}$ film is too low or too high, the $\mathrm{Cu}$ nanoparticle array cannot form. The $350 \mathrm{~nm}$ PS monolayer colloidal crystal was used as the template. The time of ionsputtering deposition is different, and the thickness of $\mathrm{Cu}$ shell is different. Fig. 4 shows the SEM images of $\mathrm{Cu}$
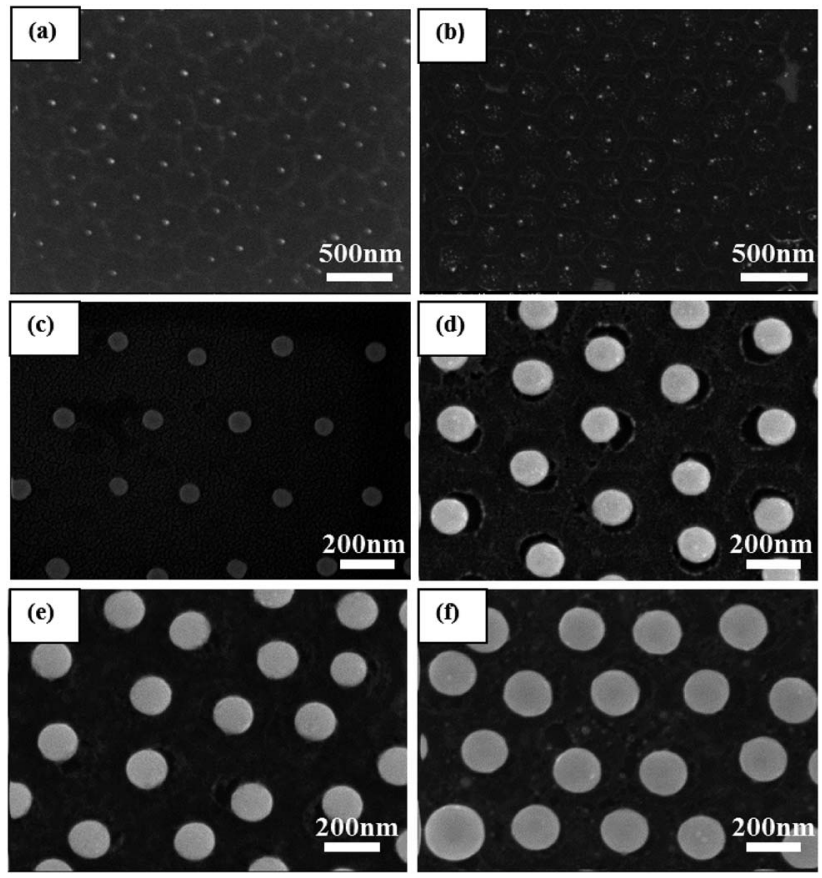

Fig. 4 SEM images of the Cu nanoparticles with different deposition times: (a) $1 \mathrm{~min}$, (b) $2 \mathrm{~min}$, (c) $3 \mathrm{~min}$, (d) $6 \mathrm{~min}$, (e) $9 \mathrm{~min}$, and (f) $18 \mathrm{~min}$, the deposition current is $20 \mathrm{~mA}$. nanoparticles annealed from different predecessors. When the deposition time was $1 \mathrm{~min}$ and the current was $20 \mathrm{~mA}$, the PS nanospheres disappeared after annealing, and the uneven $\mathrm{Cu}$ nanoparticles had a small size in the hexagon area. As shown in Fig. 4a, in the area of each hexagon profile, there is a particle, but the size of the particle is very uneven and has no profile. It suggests that the $1 \mathrm{~min}$ deposition time is too short to form a neat and orderly array. As shown in Fig. 4b, when the deposition time is $2 \mathrm{~min}$, the large $\mathrm{Cu}$ nanoparticle distribution with multiple small particles is in the area of each hexagon profile. When the deposition time is $3 \mathrm{~min}$, the $\mathrm{Cu}$ nanoparticles are significantly bigger than before, and the surrounding small particles disappear. The diameter of $\mathrm{Cu}$ nanoparticles is about $70 \mathrm{~nm}$ (shown in Fig. 4c). When the deposition time increased to $6 \mathrm{~min}$ and $9 \mathrm{~min}$, the diameter of the $\mathrm{Cu}$ nanoparticles is $120 \mathrm{~nm}$ (shown in Fig. 4d) and $150 \mathrm{~nm}$, respectively (shown in Fig. 4e), and the morphology of the $\mathrm{Cu}$ nanoparticles is uniformly spherical and show a hexagonal non-closed-packed arrangement. When the deposition time was increased to $18 \mathrm{~min}, \mathrm{Cu}$ nanoparticles became uneven (shown in Fig. 4f). To sum up, for the $350 \mathrm{~nm}$ PS monolayer colloidal crystal as the template, the deposition time should be 3-18 $\mathrm{min}$, and the diameter will be 70-200 $\mathrm{nm}$ (the deposition current was $20 \mathrm{~mA}$ ).

\subsection{Cu nanoparticle array for SERS substrates}

$\mathrm{Cu}$ nanomaterials have a similar LSPR effect as $\mathrm{Au}$ and $\mathrm{Ag}$ nanoparticles. Thus, the $\mathrm{Cu}$ nanoparticle array can be used for the SERS substrate. Because of the periodic structure, the SERS signals are stable with high reproducibility. The $\mathrm{Cu}$ nanoparticle arrays with deposition time were first immersed in $10^{-6} \mathrm{M}$ crystal violet (CV) solution for $30 \mathrm{~min}$ and subsequently rinsed with deionized water several times to remove the free or physically adsorbed molecules. After drying under ambient conditions in air, SERS characterization was conducted. Fig. 5 shows the SERS signal intensities of $\mathrm{CV}$ absorbed on the $\mathrm{Cu}$ nanoparticle arrays with different diameters. The CV molecules exhibit vibrational bands corresponding to the aromatic $\mathrm{C}-\mathrm{C}$ stretching modes at 1619, 1585, 1535, and $1444 \mathrm{~cm}^{-1}$, an $\mathrm{N}$ -

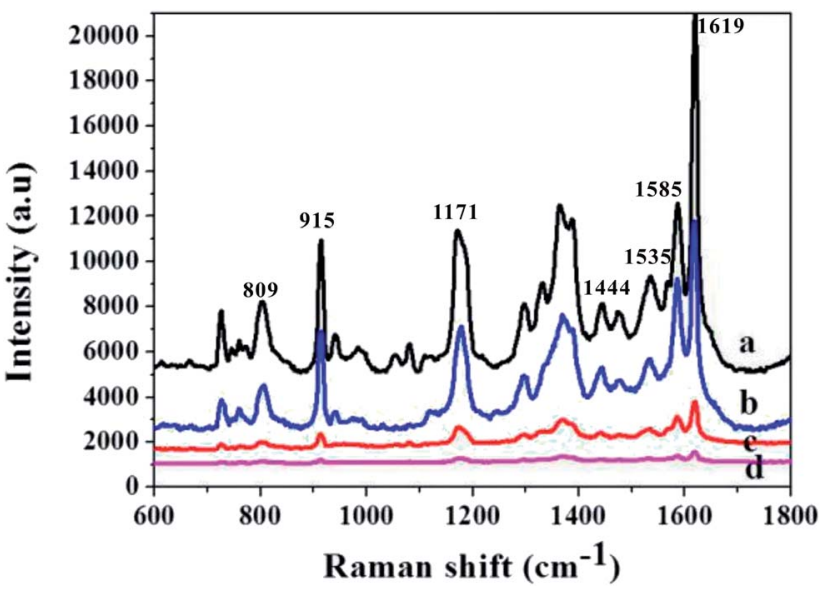

Fig. 5 Surface enhanced Raman scattering spectra of $10^{-6}$ M CV on the Cu nanoparticle arrays with different deposition times. 
phenyl stretching mode at $1370 \mathrm{~cm}^{-1}$, and aromatic $\mathrm{C}-\mathrm{H}$ bending modes at 1171,915 , and $809 \mathrm{~cm}^{-1}$. As can be seen, the 3 min deposition time has the weakest SERS signals (cave d). The $\mathrm{Cu}$ nanoparticles with $18 \mathrm{~min}$ deposition time produce the relatively significantly enhanced SERS signal (cave a). The SERS substrate at $18 \mathrm{~min}$ deposition time has a significant enhancement due to the inclusion of more particles in the unit area under $18 \mathrm{~min}$ deposition time. In addition, since the spacing between the particles is in the tens or even hundreds of nanometers, the coupling effect is not considered. Really playing a role of coupling effect is the superposition of the entire individual granules SERS effect light panel. The results demonstrate that the $18 \mathrm{~min}$ ion-sputtering deposition can improve the SERS activity. To observe the enhancement intuitively and quantitatively of the $18 \mathrm{~min}$ ion-sputtering deposited $\mathrm{Cu}$ nanoparticle arrays, the SERS enhancement factor (EF) was calculated as follows:

$$
\mathrm{EF}=\left(I_{\mathrm{SERS}} / N_{\mathrm{SERS}}\right) /\left(I_{0} / N_{0}\right)
$$

$I_{\text {SERS }}$ and $I_{0}$ are the peak intensities of the SERS measurement and the regular Raman measurement, respectively. $N_{\text {SERS }}$ and $N_{0}$ represent the numbers of the corresponding surface and solid molecules effectively excited by the laser beam, respectively. ${ }^{19}$ We used the $10^{-10} \mathrm{M}$ concentration for an estimate of the ensemble EF. On the basis of the intensity of the aromatic $\mathrm{C}-\mathrm{C}$ stretching modes at $1619 \mathrm{~cm}^{-1}$ (Fig. S4†), the average EF was calculated to be $1.6 \times 10^{7}$.

The sensitive properties of the $\mathrm{Cu}$ nanoparticle arrays will be demonstrated through SERS detections. 4-ATP solution with different concentrations $\left(10^{-4}, 10^{-5}, 10^{-6}\right.$, and $\left.10^{-7} \mathrm{M}\right)$ was prepared. Then, $2 \mu \mathrm{L}$ 4-aminothiophenol (4-ATP) was dropped on $0.3 \times 0.3 \mathrm{~cm}^{2} \mathrm{Cu}$ nanoparticle arrays with $18 \mathrm{~min}$ ionsputtering deposition. In each sample, 4-5 points are selected, and the test results are shown in Fig. 6. Herein, two sets of bands were observed in the SERS spectra of 4-ATP on the surface of $\mathrm{Cu}$ NPs: one set is located at 1076 and $1576 \mathrm{~cm}^{-1}$,
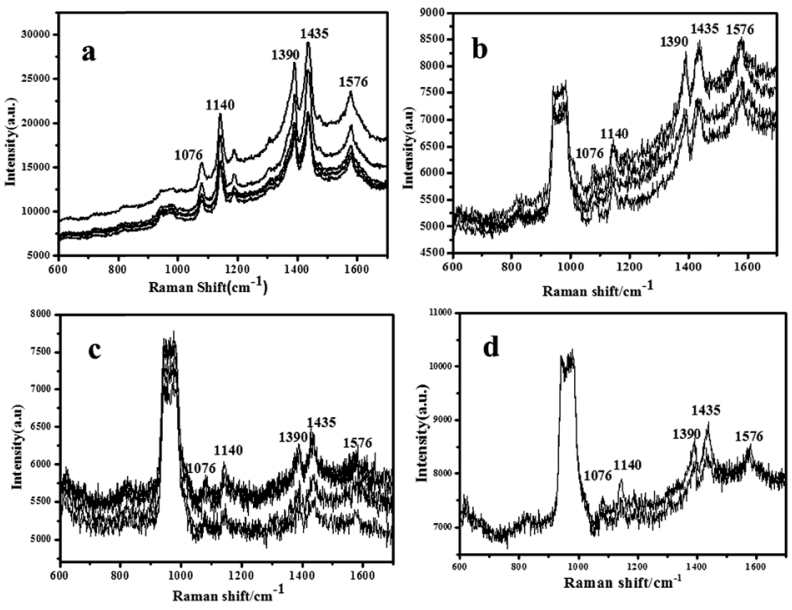

Fig. 6 Surface enhanced Raman scattering spectra for the Cu nanoparticle arrays probed with the various concentrations of 4-ATP, $10^{-4} \mathrm{M}(\mathrm{a}), 10^{-5} \mathrm{M}(\mathrm{b}), 10^{-6} \mathrm{M}$ (c), and $10^{-7} \mathrm{M}(\mathrm{d})$. which is assigned to the a1 vibrational modes, and the other set is located at 1140,1390 , and $1435 \mathrm{~cm}^{-1}$, which is assigned to the b2 vibrational modes. The $\mathrm{Cu}$ nanoparticle arrays with $18 \mathrm{~min}$ ion-sputtering deposition has a good SERS enhancement effect on 4-ATP of $10^{-4} \mathrm{M}$. The SERS signal of the selected 5 points is stable, and the width peak at the position $900 \mathrm{~cm}^{-1}$ is from the base $\mathrm{SiO}_{2}$ (shown in Fig. S5 $\dagger$ ). When the 4-ATP concentration was reduced, the SERS signals gradually decayed, and the concentrations of $10^{-5}$ and $10^{-6} \mathrm{M}$ used also showed very good SERS enhancement effect until $10^{-7} \mathrm{M}$. Integral time was increased to $14 \mathrm{~s}$ to measure the effect of the weaker concentration. No signal was detected beyond $10^{-7} \mathrm{M}$; thus, no experimental results were obtained for it.

\section{Conclusions}

In summary, the SERS activity of simple $\mathrm{Cu}$ nanoparticle arrays, which were fabricated by a one-step ion-sputtering deposition method on a PS colloidal monolayer template, with different periodic lengths was investigated using $\mathrm{CV}$ as the probe molecule. The experimental results demonstrate that the 18 min ionsputtering deposition can improve the SERS activity, and using the calcination process, the surfactant interference with the SERS effect is reduced. The SERS substrates have good stability and reproducibility. All these properties used for the SERS substrates open up a new opportunity for inexpensive SERS measurement.

\section{Conflicts of interest}

There are no conflicts of interest to declare.

\section{Acknowledgements}

This work was supported by the Top-notch Academic Programs Project of Jiangsu Higher Education Institutions (TAPP) (Grant no. PPZY2015B186) and the Postdoctoral Fellowship of China (Grant no. 2016M590579).

\section{Notes and references}

1 H. Chi, B. H. Liu, G. J. Guan, Z. P. Zhang and M. Y. Han, Analyst, 2010, 135, 1070-1075.

2 J. H. Kim, J. S. Kim, H. Choi, S. M. Lee, B. H. Jun, K. N. Yu, E. Kuk, Y. K. Kim, D. H. Jeong, M. H. Cho and Y. S. Lee, Anal. Chem., 2006, 78, 6967-6973.

3 K. Zhang, J. J. Zhao, H. Y. Xu, Y. X. Li, J. Ji and B. H. Liu, ACS Appl. Mater. Interfaces, 2015, 7, 16767-16774.

4 L. B. Yang, P. Li, H. L. Liu, X. H. Tang and J. H. Liu, Chem. Soc. Rev., 2015, 44, 2837-2848.

5 X. Gong, Y. Bao, C. Qiu and C. Y. Jiang, Chem. Commun., 2012, 48, 7003-7018.

6 B. Sharma, R. R. Frontiera, A. I. Henry, E. Ringe and R. P. Van Duyne, Mater. Today, 2012, 15, 16-25.

7 Q. Q. Ding, H. L. Liu, L. B. Yang and J. H. Liu, J. Mater. Chem., 2012, 22, 19932-19939. 
8 J. Li, C. Y. Liu and Y. Liu, J. Mater. Chem., 2012, 22, 84268430.

9 P. L. Hansen, J. B. Wagner, S. Helveg, J. R. Rostrup-Nielsen, B. S. Clausen and H. Topsoe, Atom-resolved imaging of dynamic shape changes in supported copper nanocrystals, Science, 2002, 295, 2053-2055.

10 W. Lv, J. Tian, N. Deng, Y. Wang, X. S. Zhu and X. Q. Yao, Dual-immobilized copper catalyst: carbon nitridesupported copper nanoparticles catalyzed oxidation of propargylic alcohols, Tetrahedron Lett., 2015, 56, 1312-1316.

11 Q. Lu, G. S. Hutchings, W. T. Yu, Y. Zhou, R. V. Forest, R. Z. Tao, J. Rosen, B. T. Yonemoto, Z. Y. Cao and J. G. Chen, Highly porous non-precious bimetallic electrocatalysts for efficient hydrogen evolution, Nat. Commun., 2015, 6, 1-7.

12 P. G. Sanders, J. A. Eastman and J. R. Weertman, Elastic and tensile behavior of nanocrystalline copper and palladium, Acta Mater., 1997, 45, 4019-4025.

13 X. N. Guo, C. H. Hao, G. Q. Jin, H. Y. Zhu and X. Y. Guo, Copper Nanoparticles on Graphene Support: An Efficient Photocatalyst for Coupling of Nitroaromatics in Visible Light, Angew. Chem., Int. Ed., 2014, 53, 1973-1977.
$14 \mathrm{H}$. W. Hu, J. H. Xin and H. Hu, Highly Efficient GrapheneBased Ternary Composite Catalyst with Polydopamine Layer and Copper Nanoparticles, ChemPlusChem, 2013, 78, 1483-1490.

15 K. L. Zhang, Fabrication of copper nanoparticles/graphene oxide composites for surface-enhanced Raman scattering, Appl. Surf. Sci., 2012, 258, 7327-7329.

16 W. F. Jian, W. W. Shan, H. Ling, Y. S. Wang, Y. X. Cao and X. J. Li, Surface-enhanced Raman scattering of patterned copper nanostructure electrolessly plated on arrayed nanoporous silicon pillars, J. Phys.: Condens. Matter, 2010, 22, 415105-415110.

17 Z. F. Dai, Y. Li, G. T. Duan, L. C. Jia and W. P. Cai, Phase Diagram, Design of Monolayer Binary Colloidal Crystals, and Their Fabrication Based on Ethanol-Assisted SelfAssembly at the Air/Water Interface, ACS Nano, 2012, 6, 6706-6716.

18 J. J. Wang, F. Zhou, G. T. Duan, Y. Li, G. Q. Liu and W. P. Cai, A controlled $\mathrm{Ag}-\mathrm{Au}$ bimetallic nanoshelled microsphere array and its improved surface enhanced Raman scattering effect, $R S C A d v$., 2014, 4, 8758-8763.

19 X. H. Tang, W. Y. Cai, L. B. Yang and J. H. Liu, Nanoscale, 2013, 5, 11193-11199. 